\title{
College English Teaching in Social Networking Services Based on Six Degrees of Separation
}

\author{
Xiangju Chai ${ }^{1, a^{*}}$ \\ ${ }^{1}$ School of Foreign Languages, Zhaoqing University, Zhaoqing 526061, China \\ a490380645@qq.com
}

\begin{abstract}
Keywords: Social Networking Services (SNS), Theory of Six Degrees of Separation, College English teaching
\end{abstract}

\begin{abstract}
Social Networking Services (SNS) which are based on the theory of Six Degrees of Separation emerged in 2003. With the rapid growth, it came to be a popular social service network in 2009. SNS have features that conform to learning theory of constructivism, thus having more advantages than traditional methods when employed in college English teaching. The article will explore the advantages in English teaching in universities to help students to make full use of such a tool.
\end{abstract}

\section{Introduction}

Nowadays, computer-assisted teaching of college English is widely used in many universities. With the coming of Internet Age, the English teachers and researchers have directed their attention to how to make use of internet and its technology to conduct English teaching. In universities the use of internet and its technology in English teaching has greatly improved the teaching effects and enlarged the quantity of information in classroom.

After the Internet entered into our life, Social Networking Services (SNS) have gradually become the focal spot of our communication channel, especially among college students. In the recent 10 years, the technology has developed from BBS, Blog until SNS. So far, SNS has developed into web-based services requiring people to first set up a profile (public or private) including their basic information. Usually, this process is free of charge to individuals. In recent years, online social network sites like MySpace, Face book, and Twitter are becoming the most popular sites on the Internet, in China QQ is favorite for college students. Now the latest technology of SNS, if employed in university English teaching, will play a significant role in helping the college students to achieve their learning goals. The paper will discuss the advantages of SNS in college English teaching.

\section{Social Networking Services}

Social Networking Services, a kind of application of internet, which were based on the theory of Six degrees of separation, aim to help people to build up social connections through networks. It is also known as Social Network Sites. Six degrees of separation is the theory that everyone and everything is six or fewer steps away, by way of introduction, from any other person in the world, so that a chain of "a friend of a friend" statements can be made to connect any two people in a maximum of six steps. It was originally set out by Frigyes Karinthy in 1929 and popularized by a 1990 play written by John Guare. It is Guare's piece that is most responsible for popularizing the phrase "six degrees of separation." On January 18, 2007, Kevin Bacon launched SixDegrees.org , a web site that builds on the popularity of the "small world phenomenon" to create a charitable social network and inspire giving to charities online [1]. In website, every individual's social circle is expanding, until at last it becomes a large network. So on the basis of the theory, the networking services were established eventually for the services of the society, which is the social networking service (SNS). Social networking sites allow users to share ideas, pictures, posts, activities, events, and interests with people in their network. Different from past websites which are organized according to content, SNS 
concentrate on users who are usually individuals rather than groups. This is a distinction from other online communities.

According to the Oxford Dictionary, a "social network" is a dedicated website or other application that enables users to communicate with each other by posting information, comments, messages, images, etc. The main types of social networking services are those that contain category places (such as former school year or classmates), means to connect with friends (usually with self-description pages), and a recommendation system linked to trust.

\section{The Theoretic Basis for SNS in Teaching}

According to learning theory of constructivism, learning is an active and constructive process instead of a passive one in which individuals make meanings through the interactions with each other and with the environment they live in. Knowledge is thus a product of humans and is socially and culturally constructed [2]. Social constructivists suggest that knowledge is first constructed in a social context and is then appropriated by individuals. According to social constructivists, the process of sharing individual perspectives called collaborative elaboration [3] which results in learners constructing understanding together that wouldn't be possible alone. In the end of 20th century, Constructivism had an increasing influence on teaching, leaning and curricula. Constructivists summarized four features of learning :(1) learners construct their own understanding. (2) The learners incorporate the new experience into an already existing framework. (3) Social interaction can promote learning. (4) Meaningful learning occurs when individuals are engaged in social activities. The development of mass media and computer network based on internet and its application in education and social life make it possible to build up the constructivism learning environment. Compared with previous network technology, SNS as social serving network have the characteristics of communication that can be applied in college English teaching. Social networking sites allow all the users to share ideas, pictures, posts, activities, events, and interests with people in their network. It also enables users to communicate with each other by posting information, comments, messages, images, etc.to promote the interaction between learners and construct learning environment.

\section{Advantages of SNS in College English Teaching}

In Universities, the learners are adults who can make full use of SNS in their study of English , such as to share information, to discuss a matter, to supplement a classroom teaching etc. when employed in college English teaching, SNS have many advantages which traditional teaching cannot provide.

Firstly: SNS provide large amount of information. In traditional classroom, if teachers want to supplement their classroom teaching, they must spend time and effort to collect some materials. Thus the quality and quantity of the information will be limited by the teachers' preference and their concentration, and the students' interests are neglected. By SNS, the materials can be collected by and shared among the students, in this way the supplementary materials will no doubt covers wide range and attract the students' attention and in turn it will enhance the study of a subject . This social learning online, is an excellent tool for teachers to sneak in material and ideas that students will identify with and therefore, in a secondary manner, students will learn skills that would normally be taught in a formal setting in the more interesting and engaging environment of social learning.

Secondly: The use of SNS breaks the limitation of classroom teaching. Classroom teaching is limited by the time of each period, but SNS, the network is unencumbered by time and space. Teachers can take advantage of SNS to assign learning tasks, to provide learning material, to answer question and organize discussions. These tasks are not supposed to be finished in a given time and space. Hence SNS teaching can serve as a continuity of classroom teaching. The use of SNS allow educators to enhance the prescribed curriculum. When learning experiences are infused into a website, students utilize everyday for fun, students realize that learning can and should be a part of everyday life. 
Thirdly: SNS make up for the shortcoming of large class English education. In a big class, the students are of different levels, motivation and interests, so it is difficult to conduct teaching of English in a uniform step and level. Students who would not normally participate in class are more apt to partake through social network services. Networking allows participants the opportunity for just-in-time learning and higher levels of engagement. SNS enable the students to study in accordance with their own levels and interests and in their own steps.

Fourthly: SNS strengthen the communication between the teachers and students. SNS serve as a platform for interpersonal communication, which can also be used as a tool for the communication between the teachers and the students. By means of SNS the students and the teachers can exchange ideas and views, and at the same time, by observing the information shared by the students, the teacher can have a better understanding of interests of an individual student and make use of this knowledge to improve the efficiency and effect of classroom teaching.

Next: Increasing Social Inclusion and Self-Esteem

Social inclusion is a concept in many parts of the world to characterize contemporary forms of social advantages. It refers to an access to competition, opportunities and resources including housing, employment, healthcare, civic engagement, democratic, participation, and due process. Online social networks also provide chances to make people change from social exclusion to social inclusion.

SNS offers the college students opportunities for extracurricular activities, peer group interactions, social integration, and faculty-staff interactions. It is possible that SNS provide users with a new way to get acquainted with friends avoiding confronting embarrassment in face-to-face communication. It may help people to find out the new area they have in common with others (e.g. interests, goals, experience, etc) that they have never considered before. Therefore, it may enlarge the circle of friends and promotes social inclusions.

Adolescents who frequently use an SNS had more friends on the site and also more reactions on their profile (i.e., friends posted more comments and wall posts). Instead of broad Internet use, new findings showed that online interactions contributed to more positive outcomes for youth. SNS use is related to self-esteem and psychological well-being. College students who had low self-esteem or life satisfaction might benefit more from SNS usage. In addition, the researchers reported that having more positive reactions on one's SNS profiles is correlated with higher self-esteem, and higher self-esteem is significantly correlated with satisfaction with life.

Last: SNS can improve cooperative learning. Cooperation is one of the important elements in constructivism learning, which exist not only between different students, but also between the teachers and the students, teachers and the teachers. Cooperative study is needed in the whole process of learning, such as in collecting and analyzing data; in proposing and testing of hypotheses and evaluation of achievement. Compared with traditional cooperative learning, SNS cooperation makes a breakthrough in the limitation of time and space in traditional English education. Many things, such as words, images, audios, videos, animations and many other media information can be shared by the learners and instructors. And more importantly, SNS act as a bridge of communication and thus forming interactive means between the teaching and learning. SNS provide students with the opportunity to converse and collaborate with others in real time. Social networking services provide a virtual "space” for learners.

\section{The role of teachers in a SNS English classroom}

To English teachers in a SNS classroom is a challenging job. They should act as a facilitators and not teachers [4]. The classroom is student-centered rather than teacher-centered. In the process of learning, the emphasis thus turns away from the instructor and the content, and towards the learner. A teacher gives a didactic lecture that covers the subject matter; a facilitator helps the learner to get to his or her own understanding of the content. This dramatic change of role implies that a facilitator needs to display a totally different set of skills than that of a teacher. A teacher tells, a facilitator asks; a teacher lectures from the front, a facilitator supports from the back; a teacher gives answers 
according to a set curriculum, a facilitator provides guidelines and creates the environment for the learner to arrive at his or her own conclusions; a teacher mostly gives a monologue, a facilitator is in continuous dialogue with the learners.

\section{Summary}

SNS, as a new technology are always developing, and the use in English teaching can more and more benefit both the learners and the instructors. We can easily figure out that SNS nowadays is not only a simple tool of communication, but a platform to integrate resources. As the technology develops, more applications are likely to emerge. What we should do is experiment with the technology and makes full use of the advantages to improve English teaching. With the college students SNS provide an interesting and efficient way for their English study.

\section{References}

[1] J. Gomez-arias, and L. Genin, "Beyond Monetization, Creating Value through Online Social Networks”, International Journal of Electronic Business, 7, 79-85, 2009.

[2] R. C. Clark, F. Nguyen, and J. Sweller, “Efficiency in Learning: Evidence-Based Guidelines to Manage Cognitive Load” , Pfeiffer, San Francisco, 2006.

[3] L. B. Nilson, “Teaching at Its Best: A Research-Based Resource for College Instructors” , John Wiley and Sons, San Francisco, 2010.

[4] Q. L. Lu, C.Y. Li , “Changing Roles of Teachers in Foreign Language Teaching”, Journal of Sichuan Foreign Language Institute, 1, 15-16, 2002. (in Chinese) 